\title{
Determination of aerosol optical thickness through the derivation of an atmospheric correction for short-wavelength Landsat TM and ASTER image data: an application to areas located in the vicinity of airports at UK and Cyprus
}

\author{
Diofantos G. Hadjimitsis • Chris Clayton
}

Received: 16 October 2008 /Accepted: 19 April 2009/Published online: 12 May 2009

(C) Società Italiana di Fotogrammetria e Topografia (SIFET) 2009

\begin{abstract}
Aerosol optical thickness is considered to be the most important unknown parameter of every atmospheric correction approach for removing atmospheric effects from satellite remotely sensed images. This study presents a description of the basics of the proposed atmospheric correction procedure, which combines the darkest object subtraction principle and the radiative transfer equations. The method considers the true reflectance values of the selected dark targets acquired in situ and the atmospheric parameters such as the aerosol single scattering phase function, single scattering albedo and water vapour absorption, which are also found from ground measurements. The proposed procedure is applicable to short wavelengths such as Landsat TM band 1,2 and ASTER band 1 in which water vapour absorption is negligible. The proposed image processing method has been tested successfully to determine the aerosol optical thickness on Landsat-5/TM images of the Lower Thames Valley area located to West London (UK) in the vicinity of Heathrow Airport and to Landsat TM/ETM+ and ASTER images of an area located in the vicinity of Paphos International Airport (Cyprus). The
\end{abstract}

\footnotetext{
D. G. Hadjimitsis $(\bowtie)$

Remote Sensing Laboratory, Department of Civil Engineering and Geomatics, Faculty of Engineering and Technology, Cyprus University of Technology,

P.O. Box 50329, 3036 Lemesos, Cyprus

e-mail: d.hadjimitsis@cut.ac.cy

URL: http://www.cut.ac.cy/ce/

C. Clayton

School of Civil Engineering and the Environment,

University of Southampton,

Highfield,

Southampton SO17 1BJ, UK
}

determined aerosol optical thicknesses for the Heathrow Airport area were $0.60,013$ and 0.75 for the Landsat TM images $(0.45-0.52 \mu \mathrm{m})$ acquired on 17 th of May 1985, 2nd of June 1985 and 4th of July 1985 . The determined aerosol optical thicknesses for the ASTER $(0.52-0.60 \mu \mathrm{m})$ images acquired on the 4th of February 2008, 26th of February 2008, 17th of December and 24th of December 2007 were $0.18,0.39,0.49$ and 0.90 , respectively. The accuracy assessment applied using the in situ spectroradiometric and sun-photometer data during the satellite overpass acquired on July-August 2008 for the Paphos area in Cyprus shows satisfactory results both for removing the atmospheric effects and for determining the aerosol optical thickness. Indeed, the high correlation between the determined aerosol optical thickness and those extracted from the visibility values increases the potential of the proposed method.

Keywords Aerosol optical thickness · Landsat TM . ASTER $\cdot$ Atmospheric correction

\section{Introduction}

The objective of any atmospheric correction method is to determine the atmospheric effects. A promising use of the determined atmospheric effects is to examine how the atmospheric pollution can be assessed through the derived aerosol optical parameters. Several methods for removing atmospheric effects have been developed from various researchers either simple or sophisticated (Hadjimitsis 1997; Hadjimitsis et al. 1999a,b; Hadjimitsis et al. 2004). One of the simplest atmospheric correction methods is the darkest 
object subtraction (DOS) approach or darkest pixel method (DP) (Campbell 1993). The DOS approach assumes that the pixel with the lowest digital number (DN) in each band should, in reality, be zero, and therefore, its radiometric DN value represents the atmospheric additive effect (Crane 1971; Crippen 1987; Campbell 1996; Hadjimitsis et al. 2003). The DP may correspond to a large water body or other dark object or feature within the scene. The principle of the DP approach is that most of the signal reaching a satellite sensor from a dark object is contributed by the atmosphere at visible wavelengths. Therefore, the pixels from dark targets are indicators of the amount of upwelling path radiance in that band. The atmospheric path radiance adds to the surface radiance of the dark target, giving the target radiance at the sensor. The surface radiance of the dark target is approximated as having zero surface radiance or reflectance. A recent adaptation of the DP method is to assume a known non-zero surface reflectance of the dark target (Hadjimitsis et al. 2003).

Several authors have shown how the DP approach can be used to determine the aerosol optical thickness (Griccs 1975; Kaufman and Sendra 1988; Kaufman et al. 1990; Hill and Sturm 1991; Gilabert et al. 1994). Hadjimitsis et al. (2003) found that two versions of the DP method have been widely used in any atmospheric correction procedure: the simplest one involves the assumption that dark areas have $0 \%$ target reflectance and the recorded reflectance corresponds to the effect of the atmosphere; the second states that the reflectance of a dark object (e.g. lake, ocean etc.) is low but not zero and an assumed value of surface reflectance (either obtained from ground measurements or from the literature) for that target can be used (Teillet and Fedosejevs 1995; Hadjimitsis 2008). The first version of the DP method is simple, and by ignoring atmospheric transmittance and diffuse sky irradiance, the atmospheric path radiance can be calculated. However with the second method, by using RT calculations, the aerosol optical depth can be determined (Teillet and Fedosejevs 1995). This paper describes briefly the derivation of a simple atmospheric correction procedure, which combines both the DOS principle and the basic radiative transfer calculations. Indeed, based on this new approach, by considering the 'standard reflectance values' at ground level of the selected dark targets, the aerosol optical thickness is determined. This approach is easy to implement and can be easily applied through the ERDAS IMAGINE 9.3 Modeller.

The proposed method differs from the traditional DOS method in the following ways:

- The method incorporates the true reflectance value, which is acquired from in situ spectro-radiometric measurements of selected pseudo-invariant dark targets. Such targets can be asphalt areas, water treatment reservoirs or dams, which are common in any geographical area.
- The method combines both the basic principles of DOS and radiative transfer equations by incorporating in the calculations the aerosol single scattering phase function, single scattering albedo and water vapour absorption (i.e. relative humidity) values as acquired from several in situ measurements for similar areas in the vicinity of airports.

Only the simplest method, the DOS (also known as the DP) correction method has been found to provide a reasonable and effective correction in the visible Landsat bands (1, 2 and 3) from the critical assessment made by Hadjimitsis et al. (2004) using ground spectro-radiometric measurements. The separate application of radiative transfer models, such as MODTRAN, 6S did not provide accurate results during this assessment study (Hadjimitsis et al. 2004). The need to develop a combined procedure in which empirical calculations will address the computation of several other atmospheric parameters through a certain procedure is apparent in this study.

\section{Determination of the aerosol optical thickness}

The extraction of aerosol optical thickness (AOT) from largescale air pollution areas provides a mean to further assess the air pollution in these areas (Kaufman et al. 1990; Paronis and Sifakis 2003; Tulloch and Li 2004). The main sources of formation of aerosols (particulates) come from emissions of gasses mainly due to man-made and natural sources (Department of the Environment 1996). Several attempts have been made to assess atmospheric pollution by correlating the derived AOT with a number of inter-related air pollutants (for example, Sifakis and Deschamps 1992; Retalis 1998; Tulloch and Li 2004; Hadjimitsis 2008); however, the problem of how to relate AOT with suspended particulate matter near the ground and then to relate it with hazardous aerosol pollutants is still an open question (Gupta et al. 2006). Several researchers show how the columnar satellite-derived AOT values relate with surface PM2.5 mass measurements (van Donkelaar et al. 2006; Engel-Cox et al. 2006). Indeed, this AOT-PM2.5 relationship can be used to convert the satellite measurements to air quality indices. While satellites can provide reliable, repeated and synoptic measurements from space, monitoring surface level air pollution continues to be a challenge since most satellite measurements are column-integrated quantities.

The proposed procedure has been developed to be applicable to short wavelengths like Landsat TM bands 1 and $2(0.45-0.52 \mu \mathrm{m}, 0.52-0.60 \mu \mathrm{m})$ in which water vapour absorption is negligible (Forster 1984; Kaufman 1989) and the water leaving radiance is not very low, so that it can be compared with other bands (like Landsat TM band 4) avoiding any errors of quantifying very dark targets. Griccs 
(1975) found that MSS band $4(0.8-1.1 \mu \mathrm{m})$ is not useful for aerosol determination due to the fact that water leaving radiances for this band are very small. However, the authors extend the proposed method to be applicable to other sensors such as the Advanced Spaceborne Thermal Emission and Reflection Radiometer (ASTER) and to wavelength ranges from 0.45 to $0.60 \mu \mathrm{m}$ based on the following factors:

- From previous research study in which an assessment of the available atmospheric correction algorithms, it has been found that the DOS works more efficiently for the wavelength region of $0.45-0.70 \mu \mathrm{m}$ (Hadjimitsis et al. 2004).

- Landsat TM-5 is a very old sensor, its radiometric accuracy is compromised and, very likely, it will end its life shortly. Landsat ETM+ has severe acquisition problems; several lines of each swath are systematically replaced by simulated values. Moreover, there are no plans to replace these sensors in the forthcoming period. Indeed, there is a great need to use other sensors such as ASTER.

The use of Earth observation to detect atmospheric pollution in different geographical areas and especially in cities has received considerable attention (for example, Kaufman and Frasrer 1983; Kaufman et al. 1990; Sifakis and Deschamps 1992; Retalis 1998; Retalis et al. 1998; Sifakis et al. 1998; Retalis et al. 1999; Wald and Balleynaud 1999; Wald et al. 1999; Hadjimitsis et al. 2002; Paronis and Sifakis 2003, Tulloch and Li 2004; Hadjimitsis and Clayton 2006; Hadjimitsis et al. 2007). All the studies have involved the determination of AOT and have used air pollution and meteorological data to support their findings. Kaufman et al. (1990) developed an algorithm for determining the AOT (using land and water dark targets) from the difference in the upward radiance recorded by the satellite between a clear and a hazy day. His method assumes that the surface reflectance between the clear day and the hazy day images does not change. Kaufman et al. (1990) recommended choosing images a short time apart and that solar zenith angles and observation angles should be as close as possible to avoid any effects of non-Lambertian surfaces, which might result in different reflectance values. Sifakis and Deschamps (1992) used SPOT images to estimate the distribution of air pollution in the city of Toulouse in France. They developed an equation to calculate the aerosol optical depth difference between one reference image (acquired under clear atmospheric conditions) and a polluted image. Their method was based on the fact that, after correction of solar and observation angle variations, the remaining deviation of apparent radiances is due to pollutants. Retalis (1998) and Retalis et al. (1999) showed that an assessment of the air pollution in Athens could be achieved using the
Landsat TM band 1 by correlating the AOT with the acquired air pollutants. They developed a new algorithm based on the optical thickness (optical density) relationship found by Sifakis and Deschamps (1992) and on the fact that reflectances of images acquired within a limited time interval are not drastically changed. Wald and Baleynaud (1999) found that Landsat TM band 6 (thermal band) is highly correlated with the amount of black particulate.

\section{Methodology}

For estimating the effects of the atmosphere, it is necessary to model all the atmospheric mechanisms in relation with the at-satellite received radiance or reflectance. Most atmospheric correction methods are based on this approach and use radiative transfer calculations to solve this problem. It is essential to formulate a RT equation in which all the interaction processes that occur can be adequately described (Chandrasekhar 1960; Cracknell and Hayes 1993). By combining the RT calculations with the DP atmospheric correction method, the following steps have been used to derive the AOT. The procedure shown below has been presented for Landsat TM short wavelengths (TM band 1 and 2) and can be applied to ASTER band 1 images.

For TM band 1, the retrieved target reflectance is approximated by (Hill and Sturm 1991; Turner and Spencer 1972; Turner 1973, Turner 1975):

$\rho_{\mathrm{tg}}=\frac{\pi \cdot\left(L_{\mathrm{ts}}-L_{\mathrm{P}}\right)}{t(\mu) \uparrow \cdot E_{\mathrm{G}}}$

where

$\rho_{\text {tg }} \quad$ is the target reflectance at ground level

$L_{\mathrm{ts}} \quad$ is the at-satellite radiance (integrated band radiance measured in $\mathrm{W} / \mathrm{m}^{2} / \mathrm{sr}$ )

$L_{\mathrm{p}} \quad$ is the atmospheric path radiance (integrated band radiance measured in $\mathrm{W} / \mathrm{m}^{2} / \mathrm{sr}$ )

$E_{\mathrm{G}} \quad$ is the global irradiance reaching the ground

$t(\mu) \uparrow$ is the direct (upward) target-sensor atmospheric transmittance

For a dark object such as a large water reservoir, the target reflectance at ground level $\left(\rho_{\mathrm{tg}}=\rho_{\mathrm{dg}}\right)$ is very low but is not zero. From this large reservoir, the DP will be seen at-satellite to have radiance $L_{\mathrm{ts}}=L_{\mathrm{ds}}$. Therefore, Eq. 1 can be re-written as:

$\rho_{\mathrm{dg}}=\frac{\pi \cdot\left(L_{\mathrm{ds}}-L_{\mathrm{P}}\right)}{t(\mu) \uparrow \cdot E_{\mathrm{G}}}$

where

$\rho_{\mathrm{dg}}$ is the dark target reflectance at ground level

$L_{\mathrm{ds}}$ is the dark target radiance at the sensor in $\mathrm{W} / \mathrm{m}^{2} / \mathrm{sr}$ 
By ignoring any absorption from ozone or water vapour and by using the equation given by Hill and Sturm (1991), the global irradiance reaching the target $E_{\mathrm{G}}$ is

$E_{\mathrm{G}}=E_{0} \cdot \exp \left[-\left(1 / 2 \tau_{\mathrm{r}}+1 / 6 \tau_{\mathrm{a}}\right) /\left(\mu_{0}\right)\right]$

where

$E_{0}$ is the solar irradiance at the top of the atmosphere in $\mathrm{W} / \mathrm{m}^{2}$

$\tau_{\mathrm{r}} \quad$ is the Rayleigh optical thickness

$\tau_{\mathrm{a}}$ is the AOT

$\mu_{0} \quad \mu_{0}=\cos \left(\theta_{0}\right)$

The atmospheric path radiance can be separated into two terms, the Rayleigh and aerosol path radiances (Gordon and Clark 1981) i.e.:For each TM band 1,

$L_{\mathrm{P}}=L_{\mathrm{pr}}+L_{\mathrm{pa}}$

where

$L_{\mathrm{pr}} \quad$ is the atmospheric path radiance due to Rayleigh scattering in $\mathrm{W} / \mathrm{m}^{2} / \mathrm{sr}$

$L_{\mathrm{pa}}$ is the atmospheric path radiance due to Mie (aerosol) scattering in $\mathrm{W} / \mathrm{m}^{2} / \mathrm{sr}$

For the evaluation of path radiance due to Rayleigh scattering, the equation given by Saunders (1990) and Gilabert et al. (1994) can be used

$$
\begin{aligned}
& L_{\mathrm{pr}}=\left\{\frac{\left(E_{\mathrm{O}} \cdot \cos \left(\theta_{0}\right) \cdot P_{\mathrm{r}}\right)}{4 \pi\left(\cos \left(\theta_{0}\right)+\cos \left(\theta_{v}\right)\right)}\right\} . \\
& \quad\left\{1-\exp \left[-\tau_{\mathrm{r}}\left(1 / \cos \theta_{0}+1 / \cos \theta_{v}\right)\right]\right\} \cdot t_{\mathrm{H}_{2} \mathrm{O}} \uparrow \cdot t_{\mathrm{O}_{3}} \uparrow
\end{aligned}
$$

where

$L_{\mathrm{pr}} \quad$ is the atmospheric path radiance due to Rayleigh scattering

$E_{0} \quad$ is the solar irradiance at the top of the atmosphere

$P_{\mathrm{r}} \quad$ is Rayleigh scattering phase function

$\theta_{0} \quad$ is the solar zenith angle

$\theta_{\mathrm{v}} \quad$ is the sensor viewing angle

$\tau_{\mathrm{r}} \quad$ is the Rayleigh optical thickness

$t_{\mathrm{H}_{2} \mathrm{O}} \uparrow \quad$ is the transmittance factor due to water vapour

$t_{\mathrm{O}_{3}} \uparrow \quad$ is the transmittance factor due to ozone

The effect of ozone and water vapour absorption in the Landsat TM band 1 is considered negligible (Forster 1984). Therefore $t_{\mathrm{H}_{2} \mathrm{O}} \uparrow=1$ and $t_{\mathrm{O}_{3}} \uparrow=1$. The Rayleigh optical thickness, $\tau_{\mathrm{r}}$, and the Rayleigh scattering phase function $P_{\mathrm{r}}$ are well established (Hill 1993; Sturm 1981). These can be calculated using Eqs. 7 and 8. The single scattering phase function $P\left(\mu_{0}\right)$ is used to describe the angular distribution of the radiation scattered by aerosol particles (Mie scattering) and gas molecules (Rayleigh scattering). The definition of Rayleigh phase function $P_{\mathrm{r}}\left(\mu_{0}\right)$ is well established and is given by equation (Aranuvachapun 1986; Sturm 1981, 1983; YiI-Yi 1982; Forster 1984; De Haan et al. 1991; Hill 1993)

$P_{\mathrm{r}}\left(\mu_{0}\right)=\frac{3}{4}\left(1+\cos ^{2} \psi\right)$

where

$\psi \quad$ is the scattering angle

For nadir viewing satellite systems, $\theta_{v} \cong 0^{\circ}$ and $\psi \cong$ $180^{\circ}-\theta_{0}$ (Gilabert et al. 1994), therefore

$P_{\mathrm{r}}\left(\mu_{0}\right)=\frac{3}{4}\left(1+\cos ^{2} \theta_{0}\right)$

Sturm (1981) reports that for most applications in remote sensing the approximate expression given below is sufficiently accurate.

$\tau_{\mathrm{r}}\left(\lambda_{\mathrm{c}}\right)=0.00879 . \lambda_{\mathrm{c}}^{-4.09}$

where

$\lambda_{\mathrm{C}}$ is the central wavelength

The AOT was calculated using the formula given by YiIYi (1982):

$$
\begin{aligned}
L_{\mathrm{pa}}= & \omega_{\mathrm{a}}\left\{\frac{\left(E_{\mathrm{O}} \cdot \cos \left(\theta_{0}\right) \cdot P_{\mathrm{a}}\right)}{4 \pi\left(\cos \left(\theta_{0}\right)+\cos \left(\theta_{v}\right)\right)}\right\} . \\
& \left\{1-\exp \left[-\tau_{\mathrm{a}}\left(1 / \cos \theta_{0}+1 / \cos \theta_{v}\right)\right]\right\} \cdot t_{\mathrm{H}_{2} \mathrm{O}} \uparrow \cdot t_{\mathrm{O}_{3}} \uparrow . \\
& \exp \left[-\tau_{\mathrm{r}}\left(1 / \cos \theta_{0}+1 / \cos \theta_{v}\right)\right]
\end{aligned}
$$

where

$L_{\text {pa }} \quad$ is the atmospheric path radiance due to Mie (aerosol) scattering in $\mathrm{W} / \mathrm{m}^{2} / \mathrm{sr}$

$\omega_{\mathrm{a}}$ is the aerosol single scattering albedo

$P_{\mathrm{a}} \quad$ is the aerosol scattering phase function

$\tau_{\mathrm{a}}$ is the AOT

The direct (upward) target-sensor atmospheric transmittance found in Eq. 2 can be determined using the following equation:

$t\left(\theta_{v}\right) \uparrow=\exp \left(-\tau / \cos \theta_{v}\right)$

The aerosol single scattering albedo $\left(\omega_{\mathrm{a}}\right)$ denotes the ratio between the aerosol scattering coefficient and the total extinction coefficient (scattering + absorption) (Kaufman 1989). From measurements of the single scattering albedo at ground level, Waggoner et al. (1981) found for urban and residential areas $\omega_{\mathrm{a}}$ ranges from 0.73 to 0.87 and for remote areas $\omega_{\mathrm{a}}$ ranges from 0.89 to 0.95 . The areas under investigation are considered as urban and suburban with residential regions, so a value of $\omega_{\mathrm{a}}=0.80$ is used here as approximation. If the aerosol single scattering albedo is 
equal to 1 , this corresponds to a perfectly scattering aerosol (Chandrasekhar 1960).

The aerosol phase function $P_{\mathrm{a}}\left(\mu_{0}\right)$ is difficult to be estimated accurately because of the great variability of aerosol particles. Several authors refer to the use of approximate relations for estimating the $P_{\mathrm{a}}\left(\mu_{0}\right)$ (Turner et al. 1971; Sturm 1981; Hill 1993). Turner et al. (1971) provide some graphs of these functions in terms of wavelength by considering a continental type aerosol. Forster (1984) used the graphical method of Turner et al. graphical method and suggested using $P_{a}\left(\mu_{0}\right)$ at $\lambda=0.7 \mu \mathrm{m}$ for all wavelengths, since the $P_{\mathrm{a}}\left(\mu_{0}\right)$ does not change significantly with wavelength. Another way to determine $P_{\mathrm{a}}\left(\mu_{0}\right)$ is to use the Henyey-Greenstein phase function (Gordon 1976; Gilabert et al. 1994; Kneizys et al. 1983, 1988; De Haan et al. 1991). However, many aerosols are characterised by a large amount of back scattering besides the strong forward scattering. This case is modelled by the Two-term HenyeyGreenstein phase function (TTHG) (Gordon et al. 1983; Gilabert et al. 1984; De Haan et al. 1991), which has been shown to agree with the Mie scattering theoretical calculations. In this proposed procedure, the TTHG equations were used.

The remaining unknowns in Eq 2 are the AOT and the reflectance value of the dark target. The dark reflectance should be come from the range of ground measurements for some suitable dark calibration targets with non-variant reflectance values through the time. The spectral characteristics of such dark targets can be easily found in the literature or from other ground campaigns.

By combining Eqs. 2, 3, 4, 5, 6, 7, 8 and 9 and solving for $\tau_{\mathrm{a}}$, the optical thickness due to particulate matter (aerosols) can be calculated. The key parameters in the above suggested procedure are the at-satellite radiance from a dark object at ground level and the aerosol scattering phase function. In this case, the approximation parameters and the TTHG equation were used to model hazy atmosphere with continental aerosols (Gilabert et al. 1994; Hill and Sturm 1991). By selecting TM band 1, in which the absorption is assumed to be minimum, and by using images acquired over a short interval time (Kaufman et al. 1990) with a nearly constant range of relative humidity, scattering due to molecules and particulate matter were assumed to represent solely the atmospheric path radiance term. Furthermore, it was assumed that the water optical properties during the short period of times did not change dramatically.

The suggested method is an empirical one based on theoretical calculations of atmospheric modelling. In order to make the computations manageable, certain approximations about atmospheric parameters such as aerosol single scattering phase function and single scattering albedo have been made. Based on the fact that, with atmospheric modelling, it is difficult to determine the real atmospheric conditions (Griccs 1975), some errors are expected.

The key assumptions that correspond to the proposed algorithm are the following:

- The surface dark target reflectance does not vary between the images

- The effects of multiple-scattering are neglected,

- Relative humidity does not have a significant effect on aerosols (absorption)

In the proposed method, secondary contributions to the atmospheric path radiance from the surrounded land are neglected.

\section{Results}

The method described in "Determination of the aerosol optical thickness", was tested on two different geographical areas, the Lower Thames Valley area in the vicinity of Heathrow Airport (UK) and Paphos District (Cyprus) for determining the AOT for specific area of interest.

\section{Heathrow Airport area (UK)}

Firstly, this method was applied to Landsat-5 TM Band 1 sub-scenes of Heathrow Airport area in the West London (see Fig. 1) acquired on 17 May 1985, 2 June 1985 and 4 July 1985 with similar solar zenith angles. This area consists of several inland water bodies, especially water storage reservoirs. Such reservoirs can be served as suitable dark targets for determining the AOT. The reservoir's ground reflectance values were obtained from the ground measurement campaign performed by Hadjimitsis (1999) using a GER1500 field spectro-radiometer. The minimum reflectance value in TM band 1 from the range of ground reflectance values was selected. These reflectance values were compared with other spectral values found in the literature such as Arenz et al. (1996) for Colorado Front Range Reservoirs. Using the DP values (in radiance) found from the masked images of reservoirs, the Rayleigh optical thickness, Rayleigh and aerosol (TTHG) phase function, the AOT was determined for each image as shown Table 1.

Visibility is closely related to the AOT, as shown by Forster (1984), Hadjimitsis and Clayton (2006) and Hadjimitsis et al. (2007). Therefore, the available visibility data found during the satellite overpass can be used as a tool for testing our determined AOT values. From Table 1, it is apparent that, in the image acquired on 4 July 1985, the AOT was significantly increased. High correlation was found by relating the visibility and determined AOT as shown by Hadjimitsis (1999). This means that aerosol concentrations might be increased on 4 July 85 due to high 
Fig. 1 Landsat TM-5 area of interest near the London Heathrow Airport Area-UK

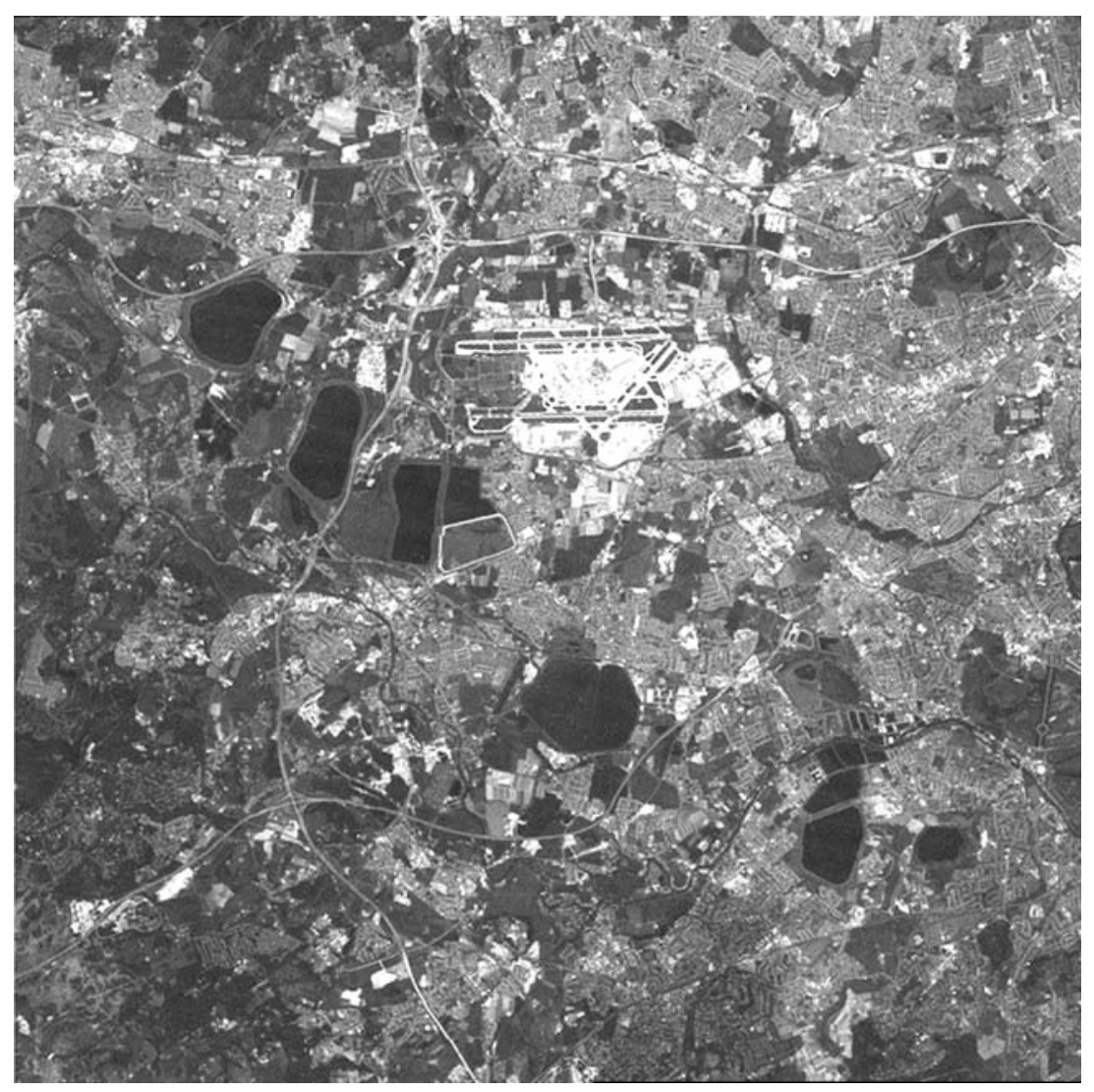

emissions from primary sources, such as road transport and industrial activities, which are the main sources of aerosol temporal variability (Department of the Environment 1996), but this needs further testing and investigation in the case where measurements of air pollutants are available. The chart provided by Forster (1984) for relating the AOT with the visibility values was used to assess the determined AOT using the proposed method. The visibility data found at the satellite overpasses in relation with the determined AOT and those found using Forster chart was in a general agreement.

\section{Paphos Airport area (Cyprus)}

The method has been tested on two Landsat TM band 1 images $(0.45-0.52 \mu \mathrm{m})$ and four ASTER $(0.52-0.60 \mu \mathrm{m})$ images.
Two Landsat-5 TM band 1 images of an area of interests District near Paphos International Airport in Cyprus (see Fig. 2) acquired on 3rd of June 1985 and 11th of May 2000 were used. Despite the 15 years difference in acquisition, both images have very similar solar zenith angles. The area of interest is concentrated at Paphos District near Paphos International Airport in which air pollution due to aircraft movements and ground support equipment provides a number of different air pollution emission sources. Asprokremmos dam (surface area, $2.1 \mathrm{~km}^{2}$ ) characterised as eutrophic inland water (Hadjimitsis et al. 2000) was used as a dark target of determining the AOT. Reflectance values at ground level for Asprokremmos dam was taken from a series of ground measurements using a GER1500 field spectroradiometer during June 1999 campaign (Hadjimitsis 1999). The determined AOT found using the proposed techniques was in a general agreement with one found

Table 1 Derived aerosol optical thickness using the proposed method for images acquired on 17 May 1985, 2 June 1985 and 4 July 1985

\begin{tabular}{cccccc} 
Image date & Solar zenith angle & Atmospheric pressure (hPa) & RH (relative humidity) (\%) & Visibility (km) & Aerosol optical thickness \\
\hline 17-May-85 & 37.02 & $1,023.3$ & 54.00 & 13 & 0.60 \\
02-June-85 & 34.60 & $1,024.9$ & 55.00 & 26 & 0.13 \\
04-July-85 & 34.92 & $1,016.00$ & 60.40 & 7.5 & 0.75 \\
\hline
\end{tabular}

Meteorological data obtained from Heathrow Airport for the satellite overpass are presented. Meteorological data are obtained every $1 \mathrm{~h}$ so an interpolation was made to match the Landsat TM overpass 
Fig. 2 Landsat TM-5 area of interest near the Paphos Airport and Asprokremmos Dam

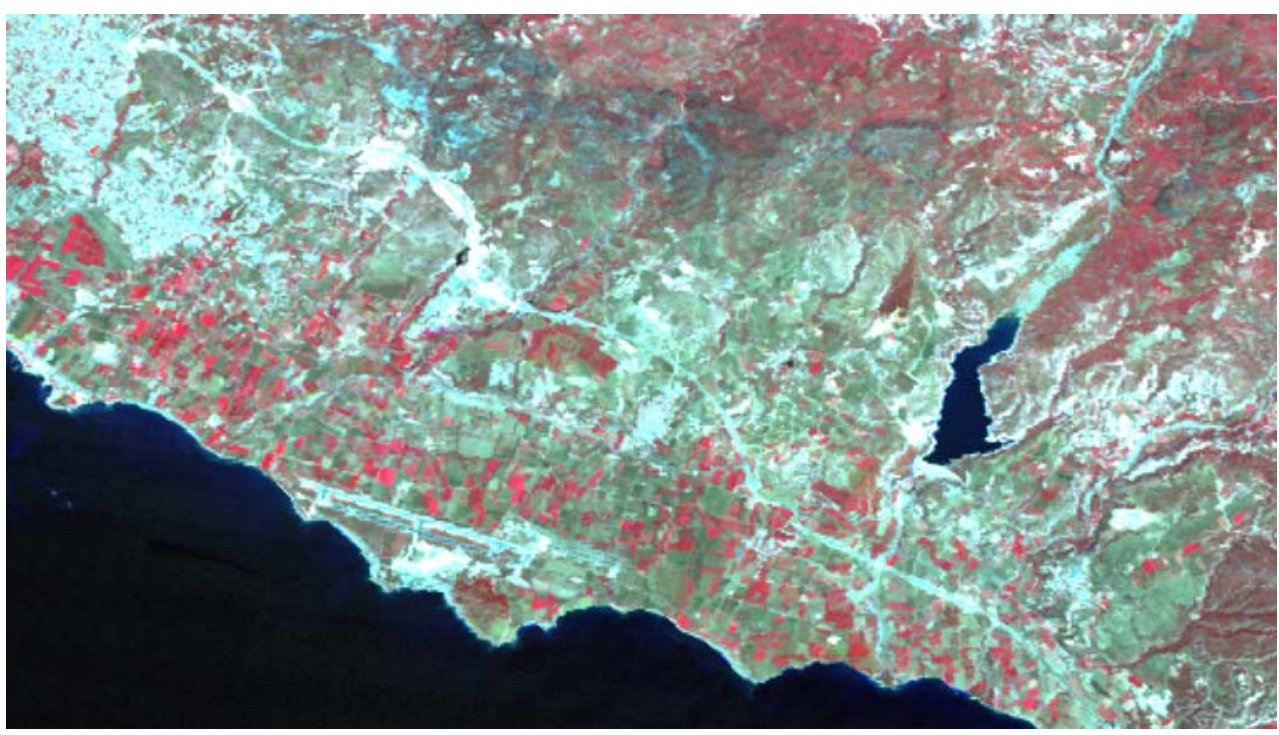

using the chart-technique presented by Forster (1984) for the Paphos area (Hadjimitsis 1999).

The proposed method has also been applied to ASTER images $(0.52-0.60 \mu \mathrm{m})$ of the Paphos airport area for four images acquired on the 4th of February and 26th of February 2008, 17th of December and 24th of December 2007 (see Fig. 3). The selected dark targets were Asprokremmos Dam and an asphalt surface at Paphos Airport. Surface reflectance values of these targets were acquired from spectroradiometric measurements obtained from a series of in situ recent and past campaigns (Hadjimitsis 1999; Hadjimitsis et al. 2009). Such targets have been found to be non-variant targets in that their reflectances do not change with time. For asphalt targets, the surface ground reflectance of $10.10 \%$ (asphalt) and 3.2\% (dam) has been used, respectively. The determined AOT is shown in Table 2. The determined AOT found using the proposed technique was in general agreement with the one found using the chart-technique presented by Forster (1984) in which visibility values are plotted against the AOT from 0.45 to $1.1 \mu \mathrm{m}$.

\section{Accuracy assessment of the method}

The proposed method has been applied to remove the atmospheric effects and determine the AOT from Landsat TM/ETM + image data of the Paphos District area in Cyprus, acquired on the 20th of July, 5th of August 2008 and 13th of August 2008. Reflectance measurements for each of the calibration/validation targets were made during the satellite overpass using a GER 1500 spectroradiometer (300-1,100 nm; nominal dispersion, $1.5 \mathrm{~nm}$; spectral resolution, $3 \mathrm{~nm}$ ). A single sensor head was used fitted with a $4^{\circ}$ lens. References to incident irradiance over a calibrated Spectralon $^{\mathrm{TM}}$ panel were obtained for every three to ten target measurements, the frequency depending on the
Fig. 3 ASTER image of interest near the Paphos Airport and Asprokremmos Dam

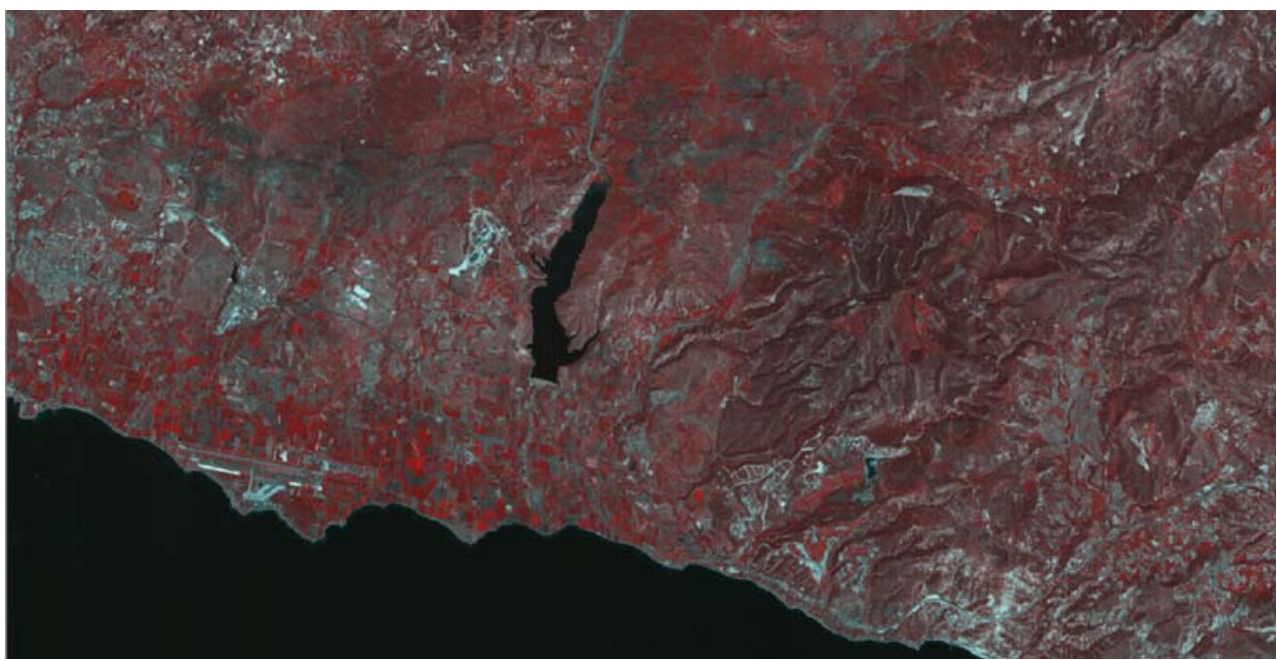


Table 2 Determined aerosol optical thickness (AOT) using ASTER band 1 images of the Paphos Airport area in Cyprus

\begin{tabular}{lc}
\hline Date of image acquisition & Determined AOT \\
\hline 04 February 2008 & 0.18 \\
26 February 2008 & 0.39 \\
17 December 2007 & 0.49 \\
24 December 2007 & 0.90 \\
\hline
\end{tabular}

degree and change of cloud cover at the time of the measurement. The GER 1500 experimental data were filtered through the relative spectral response functions and averaged within the limits of the first four TM bands to yield the in-band reflectance values. The Microtops II (Solar Light Company, USA) hand-held sun photometer that provides AOT (AOD) and columnar water vapour from instantaneous measurements, at five channels (440, 500, 670,936 , and $1,020 \mathrm{~nm}$ ) was used in this study to determine the AOT.

Other individual targets that are considered to be nonvariant targets over time, such as large asphalt and whitish soil places, have been used to assess the accuracy of the proposed method. The reflectance values for each target for each image were calculated from the ground spectral measurements, and image reflectances were derived for corresponding pixels from the calibrated after-atmospheric correction image using the determined AOT from the proposed method (1-3 pure pixels). Overall, estimated reflectances were within $\pm 2-3$ reflectance units of actual reflectances.

Indeed, by comparing the AOT obtained using the proposed method and those found using the sunphotometer, it is apparent that there is a very closed agreement between the two (see Table 3).

\section{Conclusions}

This study provides a detailed description of the derivation of an atmospheric correction method that combines radiative transfer equations and the DP principle. It has been shown by Hadjimitsis et al. (2003) that the DP is the most suitable technique for removing the atmospheric effects from cloud-free images. Therefore, the use of the DP concept in the proposed methodology for determining the AOT increases the potential of the method.

The extracted AOT from the reservoir system in the Lower Thames Valley area in the vicinity of Heathrow Airport can be used as an input parameter for models for monitoring air pollution after considering other parameters such as PM2.5, PM10 and TSP measured by standard ground air quality stations. This is a part of future research study.
Table 3 Derived aerosol optical thickness from the sun-photometer and the proposed method for the Paphos District area-Asprokremmos-Mandria area (Cyprus)

\begin{tabular}{lcc}
\hline Image date & $\begin{array}{l}\text { Aerosol optical } \\
\text { thickness obtained } \\
\text { from sun-photometer }\end{array}$ & $\begin{array}{l}\text { Aerosol optical } \\
\text { thickness obtained } \\
\text { using the proposed } \\
\text { method }\end{array}$ \\
\hline 20-July-2008 & 0.124 & 0.140 \\
05-August-2008 & 0.346 & 0.350 \\
13-May-2008 & 0.426 & 0.430 \\
\hline
\end{tabular}

The proposed algorithm is useful when dark objects such as large eutrophic reservoirs or other inland waters or asphalt surfaces are present. The algorithm is fast, practical and can be used by researchers to quantify stepby-step all the parameters involved in the sensoratmosphere-target interaction. The high correlation found between the visibility value at Heathrow Airport and the derived AOT increases the potential of the proposed method. Visibility has been found to be strongly correlated with AOT as shown in the literature (Forster 1984; Hadjimitsis 2008).

This work shows a new method of determining the AOT using large eutrophic inland waters and asphalt places as suitable dark targets. The proposed methodology allows the determination of the AOT using Landsat TM and ASTER satellite remotely sensed images with acquired in short interval time. The proposed method has a number of advantages such as: ease of computation, such dark targets are common in many geographical areas; the method is image-based technique since the assumed dark target reflectance value can be found from the literature or other in-situ campaigns; and the methodology is a useful procedure for determining the AOT as a part of any atmospheric correction algorithm. The application of the proposed methodology in two different geographical areas increases the potential of this technique.

Generally, results of proposed technique demonstrate the potential of earth observation to support the determination of aerosol variations in different geographical areas in which dark inland water bodies are located, such as areas in the vicinity of London Heathrow Airport area and Paphos International Airport area. Taken into account that the Heathrow Airport area is an attractive area for investigating air pollution due to the local busy aircraft and road transport levels, the use of satellite remote sensing imagery, which contains large water bodies such as reservoirs, is found to be an important tool for investigating air pollution. The retrieval of AOT can be useful in other studies such as atmospheric modelling of atmospheric effects and photochemical air pollution studies. 
Acknowledgements The authors wish to acknowledge a grant from the Cyprus University of Technology for supporting this study. Thanks are also given to the Remote Sensing Laboratory of the Department of Civil Engineering and Geomatics (Cyprus University of Technology) (http//:www.cut.ac.cy/) for the provision of the GER 1500 field spectroradiometer and the Microtops II sunphotometer.

\section{References}

Arenz RF, Lewis WM, Saunders JF (1996) Determination of chlorophyll and dissolved organic carbon from reflectance data for Colorado reservoirs. Int J Remote Sens 17(8):1547-1566

Aranuvachapun S (1986) Satellite remote sensing of atmospheric optical depth spectrum. Int J Remote Sens 7(4):499-514

Campbell JB (1993) Evaluation of the dark-object subtraction technique for adjustment of multi-spectral remote sensing data. SPIE 1819:176-187

Campbell JB (1996) Introduction to remote sensing, 2nd edn. Taylor and Francis, London

Chandrasekhar S (1960) Radiative transfer. Dover, New York

Cracknell AP, Hayes LW (1993) Introduction to remote sensing. Taylor and Francis, London, pp 116-158

Crane RB (1971) Pre-processing techniques to reduce atmospheric and sensor variability in multi-spectral scanner data. Proceedings of the 7th International Symposium on Remote Sensing of Environment, Ann Arbor, University of Michigan, p 1345

Crippen RE (1987) The regression intersection method of adjusting image data for band rationing. Int J Remote Sens 8(2):137-155

Haan De, Hovenier JW, Kokke JMM, Van Stokkom HTC (1991) Removal of atmospheric influences on satellite-borne imagery: a radiative transfer approach. Remote Sens Environ 37:1-21

Department of the Environment (1996) Airborne particulate matter in the United Kingdom. December 1996, Third report of the quality of urban air review group, The University of Birmingham, Institute of Public and Environmental Health, School of Biological Sciences

Engel-Cox JA, Hoff RM, Rogers R, Dimmick F, Rush AC, Szykman JJ, Al-Saadi J, Chu DA, Zell ER (2006) Integrating lidar and satellite optical depth with ambient monitoring for 3-dimensional particulate characterization. Atmos Environ 40(40):8056-8067

Forster BC (1984) Derivation of atmospheric correction procedures for Landsat MSS with particular reference to urban data. Int J Remote Sens 5(5):799-817

Gilabert MA, Conese C, Maselli F (1994) An atmospheric correction method for the automatic retrieval of surface reflectances from TM images. Int J Remote Sens 15(10):2065-2086

Gordon HR (1976) Radiative transfer: a technique for simulating the ocean in satellite remote sensing calculations. Appl Optics 15 (8):1974-1979

Gordon HR, Clark DK (1981) Clear water radiances for atmospheric corrections of CZCS imagery. Appl Optics 20:4175-4180

Gordon HR, Clark DK, Brown JW, Evans RH, Broenkow WW (1983) Phytoplankton pigment concentrations in the Middle Atlantic Bight: Comparison of ship determinations and CZCS estimates. Appl Optics 22(1):20-36

Gupta P, Christopher SA, Wang J, Gehrig R, Lee YC, Kumar N (2006) Satellite remote sensing of particulate matter and air quality over global cities. Atmos Environ 40(30):5880-5892

Griccs M (1975) Measurements of atmospheric optical thickness over water using ERTS-1 Data. J Air Pollut Control Assoc 25:622626

Hadjimitsis DG, Clayton CRI (2006) Detecting air pollution from space using image-based method. International Conference: Proceedings of Protection and Restoration of the Environment
VIII, Crete, July, 2006, Technical University of Crete, Stevens Institute of Technology, p 589

Hadjimitsis DG (1997) Mphil transfer report. University of Surrey, Department of Civil Engineering, Guildford

Hadjimitsis DG (1999) The application of atmospheric correction algorithms in the satellite remote sensing of reservoirs. PhD thesis, University of Surrey, Department of Civil Engineering, Guildford

Hadjimitsis DG (2008) Description of a new method for retrieving the aerosol optical thickness from satellite remotely sensed imagery using the maximum contrast value principle and the darkest pixel approach. Trans GIS J 12(5):633-644

Hadjimitsis DG, Clayton CRI, Hope V.S. (1999) The application of the covariance matrix atmospheric correction in the remote sensing of reservoirs. In: Earth observations from data to information. Proceedings of the 25th Annual Conference and Exhibition of the RSS, University of Wales and Swansea, pp 623-631

Hadjimitsis DG, Clayton CRI, Hope VS, Retalis A (1999) A new method of removing atmospheric effects using pseudo-invariant targets. In: Earth observations from data to information. Proceedings of the 25th Annual Conference and Exhibition of the RSS, University of Wales and Swansea, pp 633-641

Hadjimitsis DG, Clayton CRI, Hope VS (2000) The importance of accounting for atmospheric effects in satellite remote sensing: a case study from the lower thames valley area. UK. Space and Robotics 2000, February 2000, New Mexico, USA, sponsored by the ASCE and co-sponsored by NASA and SANDIA National Laboratories, pp 194-201

Hadjimitsis DG, Retalis A, Clayton CRI (2002) The assessment of atmospheric pollution using satellite remote sensing technology in large cities in the vicinity of airports. Water Air Soil Pollut 2 (5-6):631-640

Hadjimitsis DG, Clayton CRI, Retalis A (2003) Darkest pixel atmospheric correction algorithm: a revised procedure for environmental applications of satellite remotely sensed imagery. Proceedings 10th International Symposium on Remote Sensing, 8-12/9/2003, Barcelona, Spain, NASA, SPIE Conference, p 414

Hadjimitsis DG, Clayton CRI, Hope VS (2004) An assessment of the effectiveness of atmospheric correction algorithms through the remote sensing of some reservoirs. Int J Remote Sens 25 (18):3651-3674

Hadjimitsis DG, Vryonides P, Themistokleous K, Toulios L, Clayton CRI (2007) Satellite-derived determination of aerosol optical thickness for air pollution monitoring: a simplified. In: Sokhi RS and Neophytou M (eds) Proceedings of the 6th International Conference on Urban Air Quality, Limassol, Cyprus, 27-29 March 2007, University of Hertfordshire and University of Cyprus, CD-disk, ISBN 978-1-905313-46-4

Hadjimitsis DG, Clayton CRI, Retalis A (2009) The use of selected pseudo-invariant targets for the application of atmospheric correction in multi-temporal studies using satellite remotely sensed imagery. Int J Appl Earth Observ Geoinform 11:192200. doi:10.1016/j.jag.2009.01.005

Hill J (1993) High precision land cover mapping and inventory with multi-temporal earth observation satellite data. $\mathrm{PhD}$ thesis, Institute for Remote Sensing applications, Environmental mapping and modelling unit, Joint Research Centre, Commission of the European Communities, Luxembourg

Hill J, Sturm B (1991) Radiometric correction of multi-temporal Thematic Mapper data for use in agricultural land-cover classification and vegetation monitoring. Int J Remote Sens 12 (7):1471-1491

Kaufman YJ (1989) The atmospheric effect on Remote Sensing and its correction. In: Asrar G (ed) Theory and applications of optical remote sensing. Wiley, New York 
Kaufman YJ, Frasrer RS (1983) Light extinction by aerosols during summer air pollution. J Appl Meteorol 22:1694-1706

Kaufman YJ, Sendra C (1988) Algorithm for automatic atmospheric corrections to visible and near-IR satellite imagery. Int J Remote Sens 9(8):1357-1381

Kaufman YJ, Fraser RS, Ferrare RA (1990) Satellite measurements of large-scale air pollution: methods. J Geophys Res 95:9895-9909

Kneizys FX, Shettle EP, Gallexy WO, Chetwynd JH, Abreu LW, Selby JEA, Clough SA, Fenn RW (1983) Atmospheric transmittance/Radiance: Computer Code LOWTRAN 6, Air Force Geophysics Laboratory, Hanscom Air Force Base, Massachusetts

Kneizys FX, Shettle EP, Abreu LW, Chetwynd JH, Anderson GP, Gallery WO, Selby JEA, Clough SA (1988) User's guide to LOWTRAN 7, Air Force Geophysics Laboratory, Hanscom AFB Environmental Research Report ERP No.1010

Paronis D, Sifakis N (2003) Satellite aerosol optical thickness retrieval over land with contrast reduction analysis using a variable window size. Geoscience and Remote Sensing Symposium, IGARSS. Proceedings 2003. IEEE Int 2:1276-1278

Retalis A (1998) Study of atmospheric pollution in large cities with the use of satellite observations: development of an atmospheric correction algorithm applied to polluted urban areas. $\mathrm{PhD}$ thesis (in Greek), Department of Applied Physics, University of Athens, November 1998

Retalis A, Cartalis C, Asimakopoulos D (1998) An atmospheric correction algorithm applied to polluted urban cities: A cases study for Athens, Proceedings of the 24th Annual Conference and Exhibition of the Remote Sensing Society, the University of Greenwich, 9-11 September, pp 361-367

Retalis A, Cartalis C, Athanassiou E (1999) Assessment of the distribution of aerosols in the area of Athens with the use of Landsat Thematic Mapper. Int J Remote Sens 20(95):939-945

Saunders RW (1990) The determination of broad band surface from AVHRR visible and near-infrared radiances. Int J Remote Sens 11:49-67

Sifakis N, Deschamps PY (1992) Mapping of air pollution using SPOT satellite data. Photogramm Eng Remote Sensing 58:1433-1437

Sifakis N, Soulakellis NA, Paronis DK (1998) Quantitative mapping of air pollution density using earth observations: a new processing method and application to an urban area. Int $\mathrm{J}$ Remote Sens 19(17):3289-3300

Sturm B (1981) The atmospheric correction of remotely sensed data and the quantitative determination of suspended matter in marine water surface layers. Remote Sens Meteorol, Oceanogr Hydrol 147:163-197

Sturm B (1983) Selected topics of coastal zone colour scanner (CZCS) data evaluation. In: Cracknell AP (ed) Remote sensing applica- tions in marine science and technology. Springer, Berlin, pp $137-$ 167

Teillet PM, Fedosejevs G (1995) On the dark target approach to atmospheric correction of remotely sensed data. Can J Remote Sens 21(4):375-381

Tulloch M, Li J (2004) Applications of satellite remote sensing to urban air-quality monitoring: status and potential solutions to Canada. Environ Inform Arch 2:846-854

Turner RE (1973) Atmospheric effects in Remote Sensing. In: Shahrkhi F (ed) Remote sensing of earth resources. Technical papers selected from the Conference of Earth Resources Observation and Information Analysis System, Tullahoma, Tennessee, pp 549-583

Turner RE (1975) Signature variations due to atmospheric effects. Proceedings of the 10th International Symposium on Remote Sensing of the Environment, II, Ann Arbor, MI, pp 671-682

Turner RE, Spencer MM (1972) Atmospheric model for correction of spacecraft data. Proceedings of the eighth International Symposium on Remote Sensing of the Environment, II, Ann Arbor, MI, pp 895-934

Turner RE, Malila WD, Nalepka RF (1971) Importance of atmospheric scattering in remote sensing or everything you've wanted to know about atmospheric scattering but we are afraid to ask. Proceedings of the seventh International Symposium on Remote Sensing of the Environment, III, Ann Arbor, MI, pp 1651-1695

van Donkelaar A, Martin VR, Park RJ (2006) Estimating ground-level PM2.5 using aerosol optical depth determined from satellite remote sensing. J Geophys Res 111:D21201. doi:10.1029/ 2005JD006996

Wald L, Balleynaud JM (1999) Observing air quality over the city of Nantes by means of Landsat thermal infrared data. Int J Remote Sens 20(5):947-959

Wald L, Basly L, Balleynaud JM (1999) Satellite data for the air pollution mapping. Proceedings of the 18th EARseL symposium on operational sensing for sustainable development (Enschede, The Netherlands, 11-14 May 1998). In: Nieeuwenhuis GJA, Vaugham RA, Molenaar M (eds) Operational remote sensing for sustainable development. Taylor and Francis, New York, pp 133139

YiI-Yi S (1982) A method of correcting the atmospheric effects in satellite measurements of ocean colour, Proceedings of the Annual Technical Conference held in Liverpool: Remote Sensing and the Atmosphere, Remote Sensing Society, pp 110-116

Waggoner AP, Weiss RE, Ahlquist NC, Covert DS, Will S, Charlson RJ (1981) Optical characteristics of atmospheric aerosol. Atmos Environ 15:1891-1909 